\title{
Equilibrium Mechanisms in Models of Reproduction with a Fixed Budget
}

\author{
Sabir Isa Hamidov \\ Baku State University, Mathematical-Cybernetics Department, Baku, Azerbaijan
}

\section{Email address:}

sabir818@yahoo.com

To cite this article:

Sabir Isa Hamidov. Equilibrium Mechanisms in Models of Reproduction with a Fixed Budget. American Journal of Applied Mathematics. Vol. 3, No. 3, 2015, pp. 146-150. doi: 10.11648/j.ajam.20150303.21

\begin{abstract}
In the study of some models of reproduction of equilibrium mechanisms are used to describe the activity of the economic systems. As the equilibrium mechanisms models with the fixed budgets can be applied. Typically, the control center can not anticipate all situations. Hence, some variations of the initial model parameters are possible. Therefore, in the study of reproduction models a great interest presents the comparative statics, which allows one find out the dependence of the speed of changes of the state trajectories on the changes of the parameters of the trajectories. In this paper, we deal with the Leontief's type model with fixed budgets, consisting of $\mathrm{n}$ branches.
\end{abstract}

Keywords: Reproduction Model, Equilibrium Mechanisms, Lagrange Multipliers

\section{Introduction}

In studies of the reproduction models describing the activities of economic systems are often used equilibrium mechanisms. In the paper [1] as equilibrium mechanisms a model with fixed budgets is used, depending on the parameters, the prices that determine the utility function, and on the budgets of the elements of the system. Typically, the control center does not have full information about the activities of the system and can not anticipate all situations. Therefore, the study of reproduction models of great interest is a comparative statics, which allows one to find out the dependence of the speed of changes of the state trajectory generated by the mechanism on the changes in the parameters of these states.

First let us give the description of the model [1-6]. Let simulated economy consists of $n$ sectors. Each sector produces one product, and vice versa, each product is made only by one sector. Moreover, under the "product" means the whole total output of the industry. Issue of the $\mathrm{i}$ - th sector is described by the function $\mathrm{F}^{\mathrm{i}}$, for which $\mathrm{F}^{\mathrm{i}}(0)=0$ and in addition, it is assumed this function is twice continuously differentiable and strictly super linear. It means that the function $\mathrm{F}^{\mathrm{i}}$ in concave, positively homogeneous and satisfies to the inequality $F^{i}(x+y)>F^{i}(x)+F^{i}(y)$, if $x$ is not proportional toy. The state modeling the sector $\mathrm{i}$ is given by the $n$-dimensional vector $x^{i}=\left(x_{1}{ }^{i}, \ldots, x_{n}{ }^{i}\right), k-$ th coordinate of which corresponds to the $\mathrm{k}-$ th product at the disposal of this sector. As a result of industrial activity the vector the $\mathrm{x}^{\mathrm{i}}$ partially changes into the vector $\mathrm{B}^{\mathrm{i}} \mathrm{x}^{\mathrm{i}}=$ $\left(v^{\mathrm{i} 1} \mathrm{x}_{1}{ }^{\mathrm{i}}, \ldots \ldots, v^{\mathrm{in}} \mathrm{x}_{\mathrm{n}}{ }^{\mathrm{i}}\right)$. The diagonal matrix $\mathrm{B}^{\mathrm{i}}$ having $\left(v^{\mathrm{i} 1}, \ldots, v^{\mathrm{in}}\right), \quad 0 \leq v^{\mathrm{ik}} \leq 1$ as a diagonal is called a conservation matrix. Thus, expensing in the beginning of the time interval the vector $x^{i}$, at the end time the sector will have the vector $\left(\mathrm{y}_{1}{ }^{\mathrm{i}}, \ldots, \mathrm{y}^{\mathrm{i}}{ }_{\mathrm{n}}\right)$, where $\mathrm{y}_{\mathrm{k}}{ }^{\mathrm{i}}=v^{\mathrm{ik}} \mathrm{x}_{\mathrm{k}}{ }^{\mathrm{i}}(\mathrm{i} \neq$ $k), y_{i}^{i}=v^{i i} x_{i}^{i}+F^{i}\left(x^{i}\right)$.

The state of the modeling system is formed by the union of the states of the sectors, and therefore is the vector $\mathrm{X}=$ $\left(\mathrm{x}^{1}, . ., \mathrm{x}^{\mathrm{n}}\right) \in\left(\mathrm{R}_{+}{ }^{\mathrm{n}}\right)^{\mathrm{n}}$, where $\mathrm{x}^{\mathrm{i}} \in \mathrm{R}_{+}{ }^{\mathrm{n}}$ is a state of $i$-th sector.

Investigating given above model for the reproduction the model $\mathfrak{M}$ with fixed budgets is used [7], that indeed has the form

$$
\mathfrak{M}=(\{\mathrm{y}\}, \mathrm{U}, \wedge),
$$

where $y \gg 0$ is any element of the cones $R_{+}{ }^{n}, U=$ $\left(\mathrm{U}^{\mathrm{i}}, \ldots, \mathrm{U}^{\mathrm{n}}\right), \mathrm{U}^{\mathrm{i}}$ is an utility function defined as

$$
U^{i}\left(\bar{f}, x^{i}\right)=\left[\bar{f}, B^{i} x^{i}\right]+\bar{f}^{i} F^{i}\left(x^{i}\right) \quad(i=\overline{1, n}) .
$$

The functions $U^{i} \quad(i=\overline{1, n})$ indeed are the costs of all assets containing by the corresponding sector with prices $\overline{\mathrm{f}}=\left(\overline{\mathrm{f}}^{1}, \ldots, \overline{\mathrm{f}}^{\mathrm{n}}\right)$.

Note that the greatest interest is the case when the prices of the products are the same for all sectors, in other words, depend only on the products themselves. As $\wedge$ in the model 
$\mathfrak{M}$ we understand the vector $\wedge=\left(\lambda_{1}, \ldots, \lambda_{n}\right)$, the coordinate $\lambda_{\mathrm{i}}$ of which is a given budget of the $\mathrm{i}-$ th sector. The model $\mathfrak{M}$ describes the distribution of the produced product between n sectors.

The set of the vectors $\left(\mathrm{p}, \overline{\mathrm{x}}^{1}, \ldots, \overline{\mathrm{x}}^{\mathrm{n}}\right)$ forms a equilibrium state in the model $\mathfrak{M}$, if the vectors $\overline{\mathrm{x}}^{\mathrm{i}}$ are solutions of the problem

$$
\mathrm{U}^{\mathrm{i}}\left(\overline{\mathrm{f}}, \mathrm{x}^{\mathrm{i}}\right) \rightarrow \max \quad(\mathrm{i}=\overline{1, \mathrm{n}})
$$

within the conditions $\left[p, x^{i}\right]=\lambda_{i}, x^{i} \geq 0$, and in addition is valid

$$
\sum_{i=1}^{n} \bar{x}^{i}=y, p \geq 0
$$

\section{Main Body}

Let $\left(\mathrm{p}, \overline{\mathrm{x}}^{1}, \ldots, \overline{\mathrm{x}}^{\mathrm{n}}\right)$ be an equilibrium state for the model $\mathfrak{M}$. Then as shown in [7], the vector $X=\left(\bar{x}^{1}, \ldots, \bar{x}^{n}\right)$ is a solution of the following convex programming problem

$$
\begin{gathered}
\sum_{\mathrm{i}=1}^{\mathrm{n}} \lambda_{\mathrm{i}} \ln \mathrm{U}^{\mathrm{i}}\left(\overline{\mathrm{f}}, \mathrm{x}^{\mathrm{i}}\right) \rightarrow \max , \\
\sum_{\mathrm{i}=1}^{\mathrm{n}} \mathrm{x}^{\mathrm{i}}=\mathrm{y},
\end{gathered}
$$

$x^{i} \geq 0$

Here $p$ is a vector of Lagrange multipliers corresponding to the constraints (2) of this problem.

Set $\varphi_{i}\left(\bar{f}, x^{i}\right)=\lambda_{i} \ln U^{i}\left(\bar{f}, x^{i}\right), \quad(i=\overline{1, n})$.

It is clear that

$$
\nabla \varphi_{i}(\overline{\mathrm{f}}, \mathrm{x})=\frac{\lambda_{\mathrm{i}}}{\mathrm{U}^{\mathrm{i}}(\overline{\mathrm{f}}, \mathrm{x})} \nabla_{\mathrm{x}} \mathrm{U}^{\mathrm{i}}(\overline{\mathrm{f}}, \mathrm{x}) \quad(\mathrm{x}>0),
$$

And particularly

$$
\nabla \varphi_{i}\left(\bar{f}, \bar{x}^{i}\right)=\frac{\lambda_{i}}{U^{i}\left(\bar{f}, \bar{x}^{i}\right)} \nabla_{x}\left(\bar{f}, \bar{x}^{i}\right)
$$

where $\overline{\mathrm{x}}^{\mathrm{i}}=\overline{\mathrm{x}}^{\mathrm{i}}(\mathrm{f})$ is an equilibrium vector corresponding to the vector of prices $\bar{f}$.

Let us introduce the denotation $\gamma_{i}=\frac{\mathrm{U}^{\mathrm{i}}\left(\overline{\mathrm{f}}, \overline{\mathrm{x}}^{\mathrm{i}}\right)}{\lambda_{\mathrm{i}}}$. Usually the quantity $\gamma_{i}$ is interpreted as the growth rate of funds in the $\mathrm{i}$ - th sector.

Let's give each coordinate $\overline{\mathrm{f}}^{\mathrm{i}}$ of the price vector $\overline{\mathrm{f}}$ an increment $\Delta \mathrm{f}^{\mathrm{i}}$, in other words, we consider the perturbed vector of prices

$$
\mathrm{f}=\left(\overline{\mathrm{f}}^{1}+\Delta \mathrm{f}^{1}, \ldots, \overline{\mathrm{f}}^{\mathrm{n}}+\Delta \mathrm{f}^{\mathrm{n}}\right) .
$$

Consider the problem of convex programming

$$
\sum_{i=1}^{n} \tilde{\lambda_{1}} \ln U^{i}\left(f, x^{i}\right) \rightarrow \max
$$

$$
\sum_{i=1}^{n} x^{i}=y
$$

$$
x^{i} \geq 0
$$

For some $\tilde{\lambda}_{\mathrm{i}}$ and $\mathrm{f}$. Its solution $\tilde{\mathrm{x}}^{\mathrm{i}}=\tilde{\mathrm{x}}^{\mathrm{i}}\left(\tilde{\lambda}_{\mathrm{i}}, \mathrm{f}\right)$ is a component of the equilibrium state of the model $\mathfrak{M}$. Thus $\mathrm{U}^{\mathrm{i}}\left(\mathrm{f}, \mathrm{x}^{\mathrm{i}}\right)=$ $\max _{\left[\widetilde{\rho}, x^{i}\right] \leq \tilde{\lambda}_{i}, x^{i} \geq 0} U^{i}\left(f, x^{i}\right)$ and

$$
\sum_{\mathrm{i}=1}^{\mathrm{n}} \mathrm{x}^{\mathrm{i}}\left(\mathrm{f}, \tilde{\lambda}_{\mathrm{i}}\right)=\mathrm{y}, \quad \tilde{p} \geq 0 .
$$

We choose $\tilde{\lambda}_{\mathrm{i}}(\mathrm{f})$ such that (if it is possible)

$$
\frac{\tilde{\lambda}_{\mathrm{i}}(\mathrm{f})}{\mathrm{U}^{\mathrm{i}}(\mathrm{f}, \tilde{\mathrm{x}}(\mathrm{f}))}=\beta_{\mathrm{i}}
$$

where $\beta_{i}=\frac{1}{\gamma_{i}}$. By this way by prices $f$ the budgets $\tilde{\lambda}_{i}(f)$ are chosen such that the growth rate of funds in the $\mathrm{i}-$ th sector does not change by changing the price $\overline{\mathrm{f}}$. Consider the function $\tau_{i}\left(f, x^{i}\right)=\beta_{i} \nabla_{x} U^{i}\left(f, x^{i}\right)$.

It was shown in [1] that the equilibrium vector $\widetilde{\mathrm{X}}=\left(\tilde{\mathrm{x}}^{1}, \ldots, \widetilde{\mathrm{x}}^{\mathrm{n}}\right)$ is a solution of the equation $\Psi(\mathrm{f}, \mathrm{X})=0$, where $\Psi=\left(\psi_{1}, \ldots, \psi_{n}\right)$ is a mapping of $\left(R_{+}{ }^{n}\right)^{n}$ into itself, with coordinate functions

$$
\psi_{i}(X)=\tau_{i}\left(f, x^{i}\right)-\tau_{i+1}\left(f, x^{i+1}\right)
$$

by

$$
1 \leq \mathrm{i} \leq \mathrm{n}-1, \quad \psi_{\mathrm{n}}(\mathrm{X})=\sum_{1}^{\mathrm{n}} \mathrm{x}^{\mathrm{i}}-\mathrm{y} .
$$

Let us investigate the system $\Psi(\mathrm{f}, \mathrm{X})=0$ and find out the growth rate change of the trajectory by the constructed by the model $\mathfrak{M}_{\wedge, \mathrm{f}}$.

According to the implicit function theorem [8]

$$
\frac{\partial \Psi}{\partial \mathrm{f}}+\frac{\partial \Psi}{\partial \mathrm{X}} \frac{\mathrm{dX}}{\mathrm{df}}=0
$$

From this we obtain

$$
\frac{\mathrm{dX}}{\mathrm{df}}=-\left(\frac{\partial \Psi}{\partial \mathrm{X}}\right)^{-1} \frac{\partial \Psi}{\partial \mathrm{f}} .
$$

Considering $\mathrm{U}^{\mathrm{i}}\left(\mathrm{f}, \mathrm{x}^{\mathrm{i}}\right)=\left[\overline{\mathrm{f}}, \mathrm{B}^{\mathrm{i}} \mathrm{x}^{\mathrm{i}}\right]+\left[\Delta \mathrm{f}, \mathrm{B}^{\mathrm{i}} \mathrm{x}^{\mathrm{i}}\right]+\overline{\mathrm{f}}^{\mathrm{i}} \mathrm{F}^{\mathrm{i}}\left(\mathrm{x}^{\mathrm{i}}\right)+$ $\Delta \mathrm{f}^{\mathrm{i}} \mathrm{F}^{\mathrm{i}}\left(\mathrm{x}^{\mathrm{i}}\right) \quad(\mathrm{i}=\overline{1, \mathrm{n}})$,

$$
\begin{gathered}
\psi_{\mathrm{i}}(\mathrm{f}, \mathrm{X})=\left[\overline{\mathrm{f}}, \beta_{\mathrm{i}} \mathrm{B}^{\mathrm{i}}-\beta_{\mathrm{i}+1} \mathrm{~B}^{\mathrm{i}+1}\right]+\left[\Delta \mathrm{f}, \beta_{\mathrm{i}} \mathrm{B}^{\mathrm{i}}-\beta_{\mathrm{i}+1} \mathrm{~B}^{\mathrm{i}+1}\right]+ \\
\beta_{\mathrm{i}}\left(\overline{\mathrm{f}}^{\mathrm{i}}+\Delta \mathrm{f}^{\mathrm{i}}\right) \frac{\partial \mathrm{F}^{\mathrm{i}}}{\partial \mathrm{x}^{\mathrm{i}}}- \\
-\beta_{\mathrm{i}+1}\left(\overline{\mathrm{f}}^{\mathrm{i}+1}+\Delta \mathrm{f}^{\mathrm{i}+1}\right) \frac{\partial \mathrm{F}^{\mathrm{i}+1}}{\partial \mathrm{x}^{\mathrm{i}+1}}
\end{gathered}
$$

One can find 


$$
\begin{aligned}
& \frac{\partial \Psi_{\mathrm{i}}}{\partial \mathrm{f}}=\left(\beta_{\mathrm{i}} \mathrm{B}^{\mathrm{i}}-\beta_{\mathrm{i}+1} \mathrm{~B}^{\mathrm{i}+1}\right) \sum_{1}^{\mathrm{n}} \Delta \mathrm{f}^{\mathrm{i}}+\beta_{\mathrm{i}} \frac{\partial \mathrm{F}^{\mathrm{i}}}{\partial \mathrm{x}^{\mathrm{i}}} \Delta \mathrm{f}^{\mathrm{i}}- \\
& \beta_{\mathrm{i}+1} \frac{\partial \mathrm{F}^{\mathrm{i}+1}}{\partial \mathrm{x}^{\mathrm{i}+1}} \Delta \mathrm{f}^{\mathrm{i}+1}(\mathrm{i}=\overline{1, \mathrm{n}-1}), \\
& \frac{\partial \Psi_{\mathrm{n}}}{\partial \mathrm{f}}=0 .
\end{aligned}
$$

The following lemma is true.

Lemma I. The function $\Psi(\mathrm{f}, \mathrm{x})$ is differentiable with respect to $\mathrm{x}$ and $\frac{\partial \Psi}{\partial \mathrm{x}}$ coincides with the following block matrix $[9-10]$

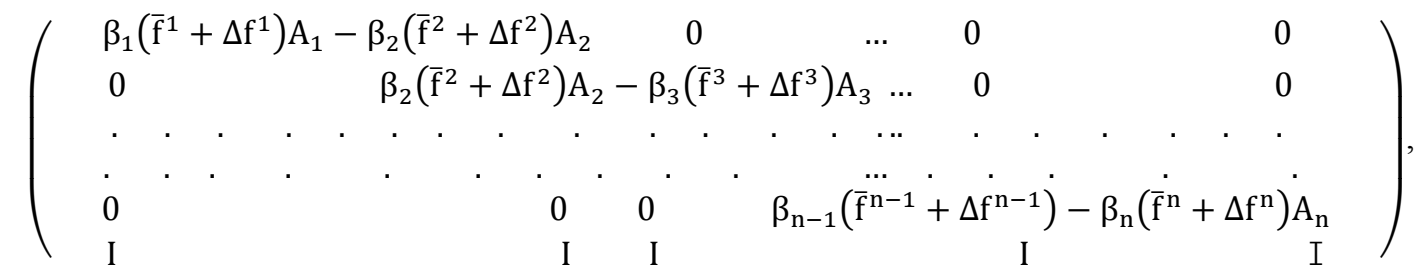

where $A_{i}=\nabla_{x}^{2} \varphi_{i}\left(\tilde{x}^{i}\right)$ is a matrix of the second partial derivatives of the function $\psi_{i}$, calculated in the point $\widetilde{\mathrm{x}}^{\mathrm{i}}$.

It is sufficient to restrict the study the case when the increment $\Delta \mathrm{f}^{\mathrm{i}}$ of the coordinates of prices, except for one (for example $\Delta \mathrm{f}^{1}$ ) are zero.

We use the following denotations

$$
\mathrm{f}=\left(\mathrm{t}, \overline{\mathrm{f}}^{2}, \ldots, \overline{\mathrm{f}}^{\mathrm{n}}\right)=\mathrm{tl}_{1}+\mathrm{g},
$$

where $\mathrm{l}_{\mathrm{i}}=(0, \ldots, 1, \ldots, 0), \quad \mathrm{g}=\sum_{\mathrm{k}=2}^{\mathrm{n}} \mathrm{f}^{-\mathrm{k}} \mathrm{l}_{\mathrm{k}}, \mathrm{t}$ is some parameter.

Then

$$
\begin{gathered}
\mathrm{U}^{1}\left(\mathrm{f}, \mathrm{x}^{1}\right)=\mathrm{t}\left[\mathrm{l}_{1} \mathrm{~B}^{1} \mathrm{x}^{1}\right]+\mathrm{tF}^{1}\left(\mathrm{x}^{1}\right) ; \\
\mathrm{U}^{\mathrm{i}}\left(\mathrm{f}, \mathrm{x}^{\mathrm{i}}\right)=\mathrm{t}\left[\mathrm{l}_{1}, \mathrm{~B}^{\mathrm{i}} \mathrm{x}^{\mathrm{i}}\right]+\left[\mathrm{g}, \mathrm{B}^{\mathrm{i}} \mathrm{x}^{\mathrm{i}}\right]+\overline{\mathrm{f}}^{\mathrm{i}} \mathrm{F}^{\mathrm{i}}\left(\mathrm{x}^{\mathrm{i}}\right) \quad(\mathrm{i}=\overline{2, \mathrm{n}}) ; \\
\frac{\partial \Psi_{1}}{\partial \mathrm{t}}=\left(\beta_{1} v^{11}-\beta_{2} v^{21}+\beta_{1} \frac{\partial \mathrm{F}^{1}}{\partial \mathrm{x}_{1}^{1}}, \beta_{1} \frac{\partial \mathrm{F}^{1}}{\partial \mathrm{x}_{2}^{1}}, \ldots, \beta_{1} \frac{\partial \mathrm{F}^{1}}{\partial \mathrm{x}_{\mathrm{n}}^{1}}\right), \\
\frac{\partial \Psi_{\mathrm{i}}}{\partial \mathrm{t}}=\left(\beta_{\mathrm{i}} v^{\mathrm{i} 1}-\beta_{\mathrm{i}+1} v^{\mathrm{i}+1,1}, 0, \ldots, 0\right) \quad(\mathrm{i}=\overline{2, \mathrm{n}-1}), \\
\frac{\partial \Psi_{\mathrm{n}}}{\partial \mathrm{t}}=0 .
\end{gathered}
$$

Take $\delta_{\mathrm{i}}=\beta_{\mathrm{i}} \mathrm{v}^{\mathrm{i} 1}-\beta_{\mathrm{i}+1} v^{\mathrm{i}+1,1} \quad(\mathrm{i}=\overline{1, \mathrm{n}-1}), \bar{\delta}_{\mathrm{i}}=\left(\delta_{\mathrm{i}}, \ldots, 0\right)$. Then $\frac{\partial \Psi_{1}}{\partial \mathrm{t}}=\bar{\delta}_{1}+\beta_{1} \frac{\partial \mathrm{f}^{1}}{\partial \mathrm{x}^{1}}, \quad \frac{\partial \Psi_{\mathrm{i}}}{\partial \mathrm{t}}=\bar{\delta}_{\mathrm{i}} \quad(\mathrm{i}=\overline{2, \mathrm{n}-1})$.

$$
\frac{\partial \Psi}{\partial \mathrm{X}}=\left(\begin{array}{ccc}
\mathrm{C}_{1} & -\mathrm{C}_{2} & 0 \\
0 & \mathrm{C}_{2} & -\mathrm{C}_{3} \\
\ldots & & \ldots \\
0 & 0 & 0 \\
\mathrm{I} & \mathrm{I} & \mathrm{I}
\end{array}\right.
$$

Here we give some axillary statements.

Lemma 2. For $n>2$ the matrix $C_{i}(i=\overline{1, n})$ is invertible and

$$
\mathrm{C}_{\mathrm{i}}^{-1}=\frac{\left(\mathrm{C}_{\mathrm{kl}}^{\mathrm{i}}\right)_{\mathrm{k}, \mathrm{l}=1}^{\mathrm{n}}}{2(\mathrm{n}-2) \mathrm{a}_{12}^{\mathrm{i}} \boldsymbol{q}_{\mathrm{i}} \mathrm{x}_{1}^{\mathrm{i}} \mathrm{x}_{2}^{\mathrm{i}}}
$$

where
The similar changes will have the matrix $\frac{\partial \Psi}{\partial X}$. In addition we transform to the more convenient form the blocks of this matrix matrix. For the elements $a^{\mathrm{i}}{ }_{\mathrm{kl}}(\mathrm{k}, \mathrm{l}=\overline{1, \mathrm{n}})$ of the matrix $A_{\mathrm{i}}(\mathrm{i}=\overline{1, \mathrm{n}})$ is valid

$$
\mathrm{a}_{\mathrm{kl}}^{\mathrm{i}}=\frac{\partial^{2} \mathrm{~F}^{\mathrm{i}}}{\partial \mathrm{x}_{\mathrm{k}}^{\mathrm{i}} \partial \mathrm{x}_{\mathrm{l}}^{\mathrm{i}}}\left(\widetilde{\mathrm{x}}^{\mathrm{i}}\right) .
$$

To express all elements of the matrix $A_{i}$ due the element $\mathrm{a}_{12}^{\mathrm{i}}$ we use known relations for the first powers of the functions (see[3]):

$$
\frac{\partial^{2} \mathrm{~F}^{\mathrm{i}}}{\partial \mathrm{x}_{1}^{\mathrm{i}} \partial \mathrm{x}_{2}^{\mathrm{i}}}-\frac{\partial^{2} \mathrm{~F}^{\mathrm{i}}}{\partial \mathrm{x}_{1}^{\mathrm{i}} \partial \mathrm{x}_{1}^{\mathrm{i}}} \frac{\mathrm{x}_{1}^{\mathrm{i}}}{\mathrm{x}_{2}^{\mathrm{i}}}=\frac{\partial^{2} \mathrm{~F}^{\mathrm{i}}}{\partial \mathrm{x}_{2}^{\mathrm{i}} \partial \mathrm{x}_{2}^{\mathrm{i}}} \frac{\mathrm{x}_{2}^{\mathrm{i}}}{\mathrm{x}_{1}^{\mathrm{i}}}
$$

As a result we get

$$
a_{k l}^{i}- \begin{cases}a_{12}^{i} \frac{x_{1}^{i} x_{2}^{i}}{x_{k}^{i} x_{k}^{i}} & (k \neq l), \\ -a_{12}^{i} \frac{x_{1}^{i} x_{2}^{i}}{\left(x_{k}^{i}\right)^{2}} & (k=1) .\end{cases}
$$

Then taking $q_{1}=\beta_{1} \mathrm{t}, q_{\mathrm{i}}=\beta_{\mathrm{i}} \overline{\mathrm{f}}^{\mathrm{i}} \quad(\mathrm{i}=\overline{2, \mathrm{n}}), \mathrm{C}_{\mathrm{i}}=$ $q_{\mathrm{i}} \mathrm{A}_{\mathrm{i}} \quad(\mathrm{i}=\overline{1, \mathrm{n}})$ we arrive to the following form of the matrix $\frac{\partial \Psi}{\partial X}$

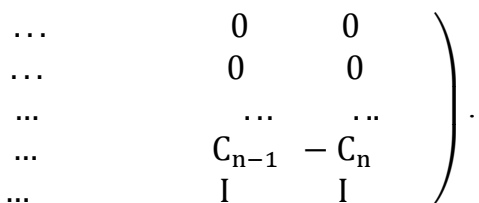

$$
\begin{aligned}
& C_{k l}^{i}=\left\{\begin{array}{c}
x_{k}^{i} x_{1}^{i}, \quad(l \neq k) \\
(3-n)\left(x_{k}^{i}\right)^{2},(l=k)
\end{array} .\right.
\end{aligned}
$$

Consequence.

$\mathrm{I}^{\mathrm{O}}$. For $\mathrm{n}=3$ the main diagonal of the matrix $\mathrm{C}_{\mathrm{i}}^{-1}$ consists of zeros.

$2^{\mathrm{O}}$. For $>3$ elements of the diagonals of the matrix $\mathrm{C}_{\mathrm{i}}^{-1}$ are positive, and all remained ones are negative. 
Lemma 3. The matrix $\frac{\partial \Psi}{\partial \mathrm{X}}$ is invertible and $\left(\frac{\partial \Psi}{\partial \mathrm{X}}\right)^{-1}=$ $\left(\mathfrak{B}_{\mathrm{kl}}\right)_{\mathrm{k}, \mathrm{l}=1}^{\mathrm{n}}$, where $\mathfrak{B}_{\mathrm{kl}}$ are square matices of order $\mathrm{n}$ defined by the (3), (4).

Let us sketch the proof of the lemma. First, we note that

$$
\operatorname{det} \frac{\partial \Psi}{\partial \mathrm{X}}=\sum_{\mathrm{k}=1}^{\mathrm{n}}\left(\prod_{\substack{\mathrm{i}=1 \\ \mathrm{i} \neq \mathrm{k}}}^{\mathrm{n}} \operatorname{detC}_{\mathrm{i}}\right)
$$

If to consider

$$
\operatorname{det} C_{i}=(-1)^{n-1}(n-2) 2^{n-1}\left(a_{12}^{i} q_{i}\right)^{n} \frac{\left(x_{1}^{i} x_{2}^{i}\right)^{n-2}}{\prod_{1=3}^{n}\left(x_{1}^{i}\right)^{2}} .
$$

Then after some transformations we have

$$
\begin{aligned}
& \operatorname{det} \frac{\partial \Psi}{\partial X}=(-1)^{n-1} 2^{(n-1)^{2}}(n- \\
& 2)^{n-1} \sum_{k=1}^{n}\left[\prod_{\substack{i=1 \\
i \neq k}}^{n}\left(a_{12}^{i} q_{i}\right)^{n} \frac{\left(x_{1}^{i} x_{2}^{i}\right)^{n-2}}{\prod_{l=3}^{n}\left(x_{1}^{i}\right)^{2}}\right] .
\end{aligned}
$$

From this we see that if

$$
x_{1}^{i} \neq 0 \quad(i=\overline{1, n}, l=\overline{1, n}) \text {, then } \operatorname{det} \frac{\partial \Psi}{\partial X} \neq 0 .
$$

Therefore there exists a matrix that is inverse to $\frac{\partial \Psi}{\partial \mathrm{X}}$.

The matrix $\left(\frac{\partial \Psi}{\partial \mathrm{X}}\right)^{-1}$ we seek in the form $\left(\frac{\partial \Psi}{\partial \mathrm{X}}\right)^{-1}=$ $\left(\mathfrak{B}_{\mathrm{kl}}\right)_{\mathrm{k}, \mathrm{l}=1}^{\mathrm{n}}$, where $\mathfrak{B}_{\mathrm{kl}} \mathrm{n}$-order square matrix. . If to consider that the product of the matrices $\left(\frac{\partial \Psi}{\partial \mathrm{X}}\right)\left(\frac{\partial \Psi}{\partial \mathrm{X}}\right)^{-1}$ is a diagonal block matrix with identity block matrices in the main diagonal, one can write out $\mathrm{n}$ system of matrix equations. As a system $\mathrm{i}(\mathrm{i}=\overline{1, \mathrm{n}})$ we consider the system of equations which is a product all lines of the matrix $\frac{\partial \Psi}{\partial \mathrm{X}}$ by i-th column of the matrix $\left(\frac{\partial \Psi}{\partial \mathrm{X}}\right)^{-1}$. After a sequence of transformations from the system with number $\mathrm{j}(1 \leq \mathrm{j} \leq \mathrm{n}-$ 1) we express $\mathfrak{B}_{\mathrm{kj}} \quad(\mathrm{k}=\overline{1, \mathrm{n}})$ :

$$
\mathfrak{B}_{\mathrm{kj}}=\left\{\begin{array}{c}
\mathrm{C}_{\mathrm{k}}^{-1} \mathrm{~K}^{-1} \sum_{\mathrm{j}+1}^{\mathrm{n}} \mathrm{C}_{\mathrm{i}}^{-1}, \quad \mathrm{k}=\overline{1, \mathrm{j}} \\
-\mathrm{C}_{\mathrm{k}}^{-1} \mathrm{~K}^{-1} \sum_{1}^{\mathrm{j}} \mathrm{C}_{\mathrm{i}}^{-1}, \mathrm{k}=\mathrm{j}+\overline{1, \mathrm{n}}
\end{array}\right.
$$

By similar way we express $\mathfrak{B}_{\mathrm{kn}}$ from the system with number $\mathrm{n}$

$$
\mathfrak{B}_{\mathrm{kn}}=\mathrm{C}_{\mathrm{k}}^{-1} \mathrm{~K}^{-1}(\mathrm{k}=\overline{1, \mathrm{n}}) .
$$

Here and later on

$$
\mathrm{K}^{-1}=\left(\sum_{\mathrm{i}=2}^{\mathrm{n}} \mathrm{C}_{\mathrm{i}}^{-1}\right)^{-1}
$$

Thus the matrix $\left(\frac{\partial \Psi}{\partial \mathrm{X}}\right)^{-1}$ is now found since all formed blocks $\mathfrak{B}_{\mathrm{kl}}(\mathrm{k}, \mathrm{l}=\overline{1, \mathrm{n}})$ are found.

$$
\text { Let } Y=\frac{d x}{d t}, \frac{d x^{i}}{d t}=y^{i} \text {. Then } Y=\left(y^{1}, \ldots \ldots, y^{n}\right) \text {. }
$$

Let us study the dependence of the sign of coordinates of the vectors $\mathrm{y}^{1}, \ldots, \mathrm{y}^{\mathrm{n}}$ on changes of the price of the first product. Now when the matrix $\left(\frac{\partial \Psi}{\partial \mathrm{X}}\right)^{-1}$ is known we can write out the system of equalities following from the theorem on implicit function

$$
y^{i}=-\beta_{1} \mathfrak{B}_{\mathrm{i} 1} \frac{\partial \mathrm{F}^{1}}{\partial \mathrm{x}^{1}}-\sum_{\mathrm{j}=1}^{\mathrm{n}-1} \mathfrak{B}_{\mathrm{ij}} \bar{\delta}_{\mathrm{j}} \quad(\mathrm{i}=\overline{1, \mathrm{n}}) .
$$

Consider the case $\bar{\delta}_{\mathrm{j}}=0$ при $1 \leq \mathrm{j} \leq \mathrm{n}-1$. This corresponds to the fact that the ratio of the growth is equal to the ratio of the coefficients of safety first product. Namely

$$
\frac{\gamma_{\mathrm{i}+1}}{\gamma_{\mathrm{i}}}=\frac{v^{\mathrm{i}+1,1}}{v^{\mathrm{i}}} \quad(\mathrm{i}=\overline{1, \mathrm{n}-1}) .
$$

One may show that from

$$
y^{i}=-\beta_{1} \mathfrak{B}_{i 1} \frac{\partial F^{1}}{\partial x^{1}} \quad(i=\overline{1, n})
$$

Follows the relations

$$
\begin{gathered}
\mathrm{y}^{\mathrm{i}=} \mathrm{C}_{\mathrm{i}}^{-1} \mathrm{C}_{\mathrm{n}} \mathrm{y}^{\mathrm{n}} \quad(\mathrm{i}=\overline{2, \mathrm{n}-1}), \\
\mathrm{y}^{1}=-\sum_{\mathrm{i}=2}^{\mathrm{n}} \mathrm{C}_{\mathrm{i}}^{-1} \mathrm{C}_{\mathrm{n}} \mathrm{y}^{\mathrm{n}} .
\end{gathered}
$$

As a result of matrix multiplication $\mathrm{C}_{\mathrm{i}}^{-1}$ and $\mathrm{C}_{n}$ we obtain a new matrix at the intersection of $\mathrm{k}$-th line and 1-th column of which stands the element

$$
\begin{gathered}
\mathcal{D}_{\mathrm{i}} \mathrm{d}_{\mathrm{kl}}=\frac{\mathrm{a}_{12}^{\mathrm{n}} q_{\mathrm{n}} \mathrm{x}_{1}^{\mathrm{n}} \mathrm{x}_{2}^{\mathrm{n}}}{2(\mathrm{n}-2) \mathrm{a}_{12}^{\mathrm{i}} q_{\mathrm{i}} \mathrm{x}_{1}^{\mathrm{i}} \mathrm{x}_{2}^{\mathrm{i}}} \frac{\mathrm{x}_{\mathrm{k}}^{\mathrm{i}}}{\mathrm{x}_{1}^{\mathrm{n}}}\left[\frac{\mathrm{x}_{1}^{\mathrm{i}}}{\mathrm{x}_{1}^{\mathrm{n}}}+\cdots+(3-\mathrm{n}) \frac{\mathrm{x}_{\mathrm{k}}^{\mathrm{i}}}{\mathrm{x}_{\mathrm{k}}^{\mathrm{n}}}+\cdots-\frac{\mathrm{x}_{1}^{\mathrm{i}}}{\mathrm{x}_{\mathrm{i}}^{\mathrm{n}}}+\right. \\
\left.\cdots \frac{\mathrm{x}_{\mathrm{n}}^{\mathrm{i}}}{\mathrm{x}_{\mathrm{n}}^{\mathrm{n}}}\right] .
\end{gathered}
$$

Hence we obtain the formula for expressing the coordinates of the vectors $y^{i} \quad(i=\overline{2, n-1})$ through the coordinates of the vectors $y^{\mathrm{n}}$

$$
\begin{gathered}
y_{j}^{i}=\mathcal{D}_{i} \sum_{l=1}^{n} d_{j l} y_{l}^{n} \quad(j=\overline{1, n}), \\
y_{j}^{1}=-\sum_{i=2}^{n} \mathcal{D}_{i} \sum_{l=1}^{n} d_{j l} y_{l}^{n} .
\end{gathered}
$$

Thus we obtain the validity of the following theorems.

Theorem 1. The speed $y^{i}$ of change of state of the $i-t h$ sector $(i=\overline{1, n-1})$ is expressed linearly through the coordinates of the $\mathrm{y}^{\mathrm{n}}$.

Tеорема 2. Let $M^{i}=\max \left\{\frac{x_{1}^{i}}{x_{1}^{n}}, \ldots, \frac{x_{n}^{i}}{x_{n}^{n}}\right\}$. If there exist small enough $\delta_{i}>0$ such that for all $\mathrm{j}=\overline{1, n}$ is true $\left|\frac{\mathrm{x}_{\mathrm{j}}^{\mathrm{i}}}{\mathrm{x}_{\mathrm{j}}^{\mathrm{n}}}-\mathrm{M}^{\mathrm{i}}\right|<\delta$, then for arbitrary small enough $\delta_{\mathrm{i}}>0$ is valid the equality

$$
\left|\mathrm{y}_{\mathrm{k}}^{\mathrm{i}}-\frac{\mathrm{a}_{12}^{\mathrm{n}} q_{\mathrm{n}}}{\mathrm{a}_{12}^{\mathrm{i}} q_{\mathrm{i}}} \mathrm{y}_{\mathrm{k}}^{\mathrm{n}}\right|<\varepsilon_{\mathrm{i}} \quad(\mathrm{i}=\overline{2, \mathrm{n}-1}, \mathrm{k}=\overline{1, \mathrm{n}})
$$


Consequence. Under the conditions of Theorem signs of the coordinates of the vectors $y^{i}$ at $1 \leq i \leq n-1$ coincide with the signs of the coordinates of the vector $y^{n}$. Coordinates of the vector $\mathrm{y}^{1}$ have the opposite sign to the corresponding coordinates of other vectors.

In other words, if you change the price of the first product in all sectors, except for the first, occurs simultaneously deceleration or acceleration of the trajectory growth, while in the first branch opposite process takes place.

\section{Conclusion}

1. The character of the variation of the speed of the model trajectory growth is defined.

2. The lemma on the differentiability of the function $\psi(f, x)$ is proved. The matrix $\frac{\partial \psi}{\partial x}$ is constructed.

3. The invertibility conditions for the matrix $C_{i}, i=\overline{1, n}$ are found.

4. The invertibility conditions for the matrix $\frac{\partial \psi}{\partial x}$ are found.

5. The change of the state speed of the sectors is defined. Author thanks K.Niftaliyeva for her vary useful assistance in preparation the paper for publication.

\section{References}

[1] Rubinov A.M. Equilibrium model type as a tool for building effective trajectories in models of reproduction. Optimization, 1987, 41 (49)

[2] Crass I.A. Mathematical models of economic dynamics. M., Sov.radio, 1976.

[3] Allen R. Mathematical savings. M., IL,1963.

[4] Gail D. The theory of linear economic models. M., IL,1963.

[5] Lancaster K. Mathematical Economics. M.,Sov.radio,1972.

[6] Polterovich V. On the stability of some of the processes of distribution funds and regulation of prices. Mathematical Economics and functional analysis. M., Nauka, 1974, s.203230 .

[7] Rubinov A.M. Mathematical model of extended reproduction, L., Nauka, 1983.

[8] Kantorovich L.V., Akilov G.P. Functional analysis. M.,Nauka, 1964.

[9] Gantmakher F.R. Matrix theory.M.,Nauka, 1967.

[10] R. Bellman, Introduction to the theory of matrices. M.,Mir, 1975. 